IRA-International Journal of Education \&

Multidisciplinary Studies

ISSN 2455-2526; Vol.17, Issue 02 (Q2, 2021)

Pg. no. 45-53.

IRA Academico Research

\title{
A Review of Multidimensional Studies on the Causes for Classroom Reticent
}

\section{Lifen Gao}

School of Foreign Studies, Yangtze University, Hubei, 434023 PRC China.

Type of Work: Peer Reviewed.

DOI: 10.21013/jems.v17.n2.p1

DOI URL: https://dx.doi.org/10.21013/jems.v17.n2.p1

How to cite this paper:

Gao, L. (2021). A Review of Multidimensional Studies on the Causes for Classroom Reticent. IRA-International Journal of Education \& Multidisciplinary Studies (ISSN 2455-2526), 17(2), 45-53. DOI. https://dx.doi.org/10.21013/jems.v17.n2.p1

(C) IRA Academico Research.

(c) EY-No This work is licensed under a Creative Commons Attribution-NonCommercial 4.0 International License subject to a proper citation to the publication source of the work.

Disclaimer: The scholarly papers as reviewed and published by IRA Academico Research are the views and opinions of their respective authors and are not the views or opinions of IRA Academico Research. IRA Academico Research disclaims any harm or loss caused due to the published content to any party.

IRA Academico Research is an institutional publisher member of Publishers International Linking Association Inc. (PILA-CrossRef), USA. IRA Academico Research is an institutional signatory to the Budapest Open Access Initiative. Hungary advocating the open access of scientific and scholarly knowledge. IRA Academico Research is a registered content provider under Open Access Initiative Protocol for Metadata Harvesting (OAI-PMH).

The journal is indexed \& included in WorldCat Discovery Service (USA), CrossRef Metadata Search (USA), WorldCat (USA), OCLC (USA), Open J-Gate (India), EZB (Germany) Scilit (Switzerland), Airiti (China), Bielefeld Academic Search Engine (BASE) of Bielefeld University, Germany, PKP Index of Simon Fraser University, Canada. 


\begin{abstract}
This study explores the causes for classroom reticent from four aspects: students, teachers, classroom environment and culture. It is found that: (1) student factors are the primary factors for learners to choose silence or participation; (2) Teachers are the key factors that affect students' participation or retention in class; (3) Classroom environment is a potential active factor that affects students' participation or silence in class; (4) Cultural value orientation has a profound impact on students' classroom participation or silence. It is concluded that long or short reticent in class is closely related to the teachers' teaching guidance style, teaching questioning strategies and teaching methods, as well as students' language ability. At the same time, it is also closely related to the value judgment and orientation of "saving face", "respecting teachers", exam-oriented culture and "silence" behavior and habits in traditional culture.
\end{abstract}

Keywords: Classroom reticent; multidimensional studies; reticent causes

\title{
1. Introduction
}

Classroom reticent comes from the gap between teachers' expectation of response and students' response. Its essence is a kind of psychological state and personality tendency that individuals are unwilling to speak in classroom communication, which seriously affects the quality of university classroom teaching (Petress, 2001:105).

\section{Research on Classroom Reticent}

The previous research on classroom reticent mainly focuses on the following four points: (1) the definition and connotation of classroom reticent: reticent is regarded as a kind of psychological characteristics, which must be attached to a certain situation, that is, classroom reticent is a silent and non-verbal communicative behavior without fixed semantics shown by students in teacher-student interaction ; (2) the types of classroom reticent: different scholars have different classification of classroom reticent such as positive classroom reticent and negative classroom reticent, emotional reticent, thinking reticent, behavior silence, individual and collective reticent, etc; (3) measurement of classroom reticent: scholars measure the degree of classroom reticent from different dimensions ; (4) the influencing factors of classroom reticent, such as class size, teaching equipment, classroom atmosphere, teachers' teaching methods, questioning strategies, personality charm, teacher-student relationship and students' individual psychological factors (Blimes, 1994; Qiao, 2010).

However, as for the function of classroom reticent, no agreement has been reached yet. On one hand, some scholars believe that reticent is a kind of "escape", which is a powerful obstacle to the creation of a dialogue class. It may lead to the alienation of the teacher-student relationship, and thus greatly reduce the teaching effect, which should be dredged in the teaching process (Petress, 2001). On other hand, some scholars believe that reticent is positive and constructive, which is the prelude to the emergence of students' wonderful ideas. It contains an opportunity to motivate students' creative development and moral improvement, and it is also a means for students to avoid risks and resist authority. Its essence is the generation of self-dialogue and meaning and the process of students' spiritual awakening. This type of reticent should be respected and understood. Unfortunately, domestic scholars focus more on the negative function of classroom silence(Schultz, 2012).

Based on the above analysis, it can be seen that scholars have not come to a consistent conclusion on the 
function of classroom reticent since it is complexity and all of the factors like personality, culture and environment, interact with one another, thus affecting the effect of classroom teaching. Therefore, it is of great significance to explore the complex causes for classroom reticent. This paper will analyze the formation mechanism of College Students' classroom reticent from four aspects: culture, environment, students and teachers.

\section{Research on Reticent Causes}

It is found that the influencing factors of classroom reticent involve four dimensions: (1) Students' personal factors: conscious classroom silence caused by one's own English and thinking proficiency, personality, gender, learning motivation, etc.; (2)Teachers' factors: teaching mode, classroom questioning method, time and degree of lesson preparation, etc; (3) environmental factors: class size, class atmosphere, teacher-student relationship, etc; (4) cultural factors: face, authority, tolerance of differences, examination-oriented culture, etc(Teng, 2009).

\subsection{Cultural Dimension}

Human society is a cultural society, and all human behaviors and activities have cultural nature and internal characteristics. Learning activities are no exception. Behind the students' reticent, introverted and self-control learning behavior are rich and complex conceptual tendencies and cultural roots embedded in the sample seal. This study attempts to analyze the cultural dimension of classroom reticent from the following theoretical perspectives: "face" theory, authority concept, "speech" difference and examination-oriented culture.

(1) "Face" theory

"Face" is one of the important factors to understand people's behavior. Generally speaking, saving face is out of the maintenance of social politeness and personal dignity. No one is an exception. For teachers and students in the classroom, "saving face" is also of great significance. It is found that "saving face" is considered to be an important reason for Chinese students reticent in class ( $\mathrm{Gu}, 2005)$.

Research shows that Asian students protect their face and others' face through reticent and keeping quiet in classroom teaching. If the students feel that their answers or discussions may cause themselves, other students or teachers to lose face, form doubts about the wisdom of teachers, and challenge the views of others, they often keep silent to save face, for they don't know how to answer and they are worried that their own ideas and views may make themselves or others lose face(King,2013).

Zhang's (2015) quantitative statistical research on college students shows that students' prosocial psychology has a direct and significant impact on students' classroom reticent. Multiple regression analysis shows that students' prosocial psychology is affected by class openness, questioning strategy and course satisfaction.

\section{(2) Authority distance between teachers and students}

The sense of high power distance in Chinese culture will deepen the gap of equal communication between teachers and students, so students will not ask questions in order not to be seen as a challenge to teachers' authority. Domestic scholars have also found that students unconsciously regard teachers as "supreme" authorities, not only afraid to ask them questions, but also afraid to answer questions and express their views in front of teachers. They think that it is a challenge and disrespect to teachers and a lack of politeness (Eisenkraft \&Yang, 2003). In addition, the study found that in the situation of high power distance between teachers and 
students, teachers become the overwhelming dominator in the classroom and students' subjectivity becomes very common. Hence, reticent has sometimes become one of the ways for students to express their dissatisfaction with teachers' teaching behavior (Zhang, 2015).

The study found that the higher the tolerance of group differences, the more positive individuals will express different opinions, and they will not worry about being ridiculed and they will not hide their views. In addition, teachers' tolerance of reticent in class is low, which means that if students can't blurt out their questions after teachers throw them out, teachers will automatically default that students don't know how to answer the questions. In the long run, students get used to it naturally, and the classroom falls into a state of collective silence, and finally, teaching becomes teachers' "monologue" (Zhang,2015).

\section{(3) Silence of speech value}

The differences between Chinese and western language cultures also lead to significant differences in students' classroom performance. Chinese or Oriental students tend to be silent in the classroom. There has been a tradition of verbal eloquence for a long time in western society. Speaking is regarded as the unique quality of an individual and the embodiment of individual rights. Speaking appropriately, unambiguously and concisely is the high-quality discourse expression pursued by Westerners, and even regarded as an excellent personality trait. East Asian students, on the other hand, prefer behavior to speech. It is the language behavior orientation that makes students obedient, modest, less or even speechless in order to avoid being sharp. Furthermore, many Chinese expressions such as: "clever words and lust", "eloquence" have obvious rhetorical meaning, so "cautious words and careful behavior" is often regarded as a virtue. The origin lies in the fact that Chinese educational tradition is deeply influenced by Confucian and Taoist cultural values (Eisenkraft \&Yang, 2003).

\section{(3) Examination-oriented Culture}

The lack of a natural language environment in domestic English learning makes examination an important means to measure students' language proficiency, while foreign scholars seldom discuss the influence of examination culture on students' classroom silence.

This exam-oriented culture of "score-supreme" makes students ignore the importance of classroom participation. Eisenkraft \&Yang (2003) mentioned in their research that traditional education attaches importance to knowledge giving and receiving, and examinations are endowed with great rights, and even the whole teaching process is serving examinations. In this exam-oriented cultural atmosphere, students have no time to take part in the class participation. The purpose of students' study is to get high marks so that they can make their parents and teachers proud. In their opinion, classroom participation is not directly related to their high scores in exams and they even think it is a waste of time. The exam-orientation culture also leads to teachers insufficient attention to students' life out of class. Chinese university education has long been influenced and constrained by traditional educational concepts and values. Students are only regarded as pure cognitive subjects, while teachers only pay attention to the systematic teaching of subject knowledge, lacking the attention to the whole life of students, and ignoring students' interest, emotion and subjective experience. In other words, teachers' educational activities are limited to the knowledge imparting and receiving area in the cognitive field, students' emotions, attitudes and experiences are suppressed in the passive acceptance of knowledge, the generativity of knowledge and skills is fading in the mechanical "lecture acceptance", and students' individual development is hindered. 


\subsection{Teacher Dimension}

The existing domestic researches pay more attention to the teacher factors that lead to students' classroom silence, mainly including four categories: teaching form, teacher-student relationship, teaching style and teachers' expectation (Ollin,2008; Teng, 2009).

\section{(1) Teachers'questioning strategies}

Teachers' inappropriate questioning strategies can also lead to students' silent response. When the class falls into collective silence, teachers tend to choose the students who have better performance or students who thought to be smarter or more diligent in learning, and they think these students are "capable" students. Poor students who are regarded in the "marginal zone" are more likely to fall into self-doubt and are more reluctant to participate in classroom interaction and become silent in class (Ollin,2008).

The time length of teachers' questions is limited, so students do not get enough time to think and keep silent. Students can not catch up with the progress, the fast pace of classroom teaching, the large amount of information. Even if the students are willing to answer, they are reluctant to answer and keep silent (Teng, 2009).

The content of teachers' questions will also affect students' classroom participation. If the question is too simple, the students are unwilling to answer; if the question is too difficult, the students are unable to answer; if the question is not open enough, the students have no intention to answer or simply shut up (Teng, 2009).

\section{(2) Teacher-student relationship}

The relationship between teachers and students is not only the most basic relationship in teaching activities but also the key factor affecting the quality of teaching. Positive teacher-student relationship will lead to an active classroom atmosphere; Negative teacher-student relationship will lead to negative evaluation and silent classroom and ineffective teaching and learning. The relationship between teachers and students involves two aspects: teachers and students. Compared with students' personality, teachers' knowledge level, moral cultivation and teaching attitude and methods play a more decisive role in establishing a good relationship between teachers and students (Teng, 2009).

Misunderstanding and general tension between teachers and students, teachers' lack of humanistic care for students, and students' fear of teachers lead to students' failure to express their real ideas in and out of class (Saylag, 2014). Teachers are called to pay attention to the majority of classroom silence producers, that is, the so-called "backward students" and "average students", to establish a harmonious relationship between teachers and students, and to eliminate teachers' authority.

\section{(3) Teaching style}

Teaching style refers to the teaching methods that teachers habitually adapt according to their own personality characteristics, or the teaching strategies commonly used in the teaching process with the characteristics of stability and uniqueness. Generally speaking, teachers' teaching styles can be divided into teacher-centered "preaching style", student-centered "autonomous style", and double subject "Socrates style". Different teaching styles have different requirements for students' abilities, which will lead to students' active participation or silence in class (Ollin, 2008). 
Teachers' reaction such as criticism, punishment, praise, encouragement and guidance will also affect students' classroom performance. The research shows that teachers' positive feedback, such as praise and encouragement, is easier to mobilize students' classroom participation initiative, which helps to improve students' autonomous ability to seek knowledge, stimulate students' interest in learning, and make students more motivated and confident to speak positively; negative response, such as criticism and punishment, may scare students who are more face-saving, timid or uncertain about their answers, which leads to inadequate teacher-student interaction. Consequently, students' knowledge and thinking ability can not be improved, their sense of learning experience is reduced, and their enthusiasm for classroom participation is declining (Ollin, 2008).

\section{(4) Teacher expectation effect}

Teacher expectation refers to the inference and prediction of current and future academic performance and general classroom behavior made by teachers to students (Petress, 2001). This expectation may eventually become reality due to the change of personal beliefs.

Teachers' expectations can be divided into positive and negative ones. Students are very sensitive to the expectations of the outside world, including the extent of their educational expectations formed in the teachers' mind. Affected by that, students will show the corresponding behavior according to the teachers' expectations in the classroom. Unfortunately, many studies on classroom reticent simply just ignore teachers' expectation of students.

\subsection{Student Dimension}

The most direct cause for students' reticent is internal factors like personality, language ability and learning style.

\section{(1) Language proficiency}

Language reticent refers to students' silence due to their limited language proficiency, which means that they can't, won't and dare not participate in classroom activities due to language trouble. That is to say, the higher the learners' language proficiency, the lower the students' classroom reticent tendency; the lower the learners' language proficiency, the more obvious the classroom reticent tendency.

A qualitative research was conducted on Chinese students studying in the United States. It found that students with a higher language proficiency have a higher level of communication ability, which will lead to students' more active participation in class and vice versa (Eisenkraft \& Yang,2003).

\section{(2) Personal characteristics}

Students' personalities are closely related to reticent in class. It is generally accepted that introverts tend to keep silent in class, while extroverts are positive in class. (Liu, 2005; Zhang, 2015).

Gender differences also have an impact on students' classroom participation or silence. It is generally found that boys are more active in class than girls, and this phenomenon becomes more obvious with the improvement of grade; women are more inclined to think independently, and rarely take the initiative to express their ideas or opinions in class (Petress, 2001). 
Students' learning motivation and attitude will affect students' silence or participation in class. The classroom performance of integrative learners is relatively stable, and the silence varies from person to person; the classroom performance of instrumental learners fluctuates significantly and is greatly affected by the external environment. However, under China's English teaching environment, learners' instrumental motivation usually get dominant and they mainly focus on passing exams and obtaining more certificates, neglecting the importance of classroom participation, which results in students' collective silence (Bosacki, 2005).

Students' emotional factors directly affect students' class participation, such as speech anxiety, lack of self-confidence, fear of making mistakes, the need to maintain a good relationship and avoid arguments (Zhang, 2015). So far, the research on the personal characteristics of classroom reticent (gender, personality, learning motivation, attitude and emotion) focuses on stability, ignoring the fact that it depends on the situation and fluctuates dynamically, which means that we can take measures and create favorable conditions in the teaching process, turn the disadvantages into advantages, stimulate students to participate in classroom activities as much as possible, and reduce negative reticent. Unfortunately, at present, no scholars have noticed the potential effect of situational personality on the change of classroom reticent, especially on the change of collective classroom reticent.

\section{(3) Learning style}

Learning style refers to a kind of regular and stable behavior when students interact with the learning environment, including cognitive aspects (analytical ability, spatial thinking ability, information processing ability and memory ability), sensory aspects and physiological aspects. It is of practical significance to understand and study the characteristics of students' learning style to improve the quality of teaching. At present, the influence of students' learning style on students' classroom reticent at home and abroad focuses on the cognition. Liu (2005) found that students with competitive, cooperative and participatory learning styles are more active in-class participation than other students, while those with avoidant, dependent and independent learning styles are less active in class participation, showing too much classroom reticent.

\subsection{Classroom Environment Dimension}

Classroom environment refers to students' perception of the classroom, social environment and psychological atmosphere. It is an important potential factor that determines the learning effect and affects students' development in an overall way. At present, academic research on classroom environment mainly focuses on two aspects: classroom atmosphere and class organization form.

\section{(1) Class atmosphere}

Classroom atmosphere refers to the sum of the interactive psychological environment that teachers and students feel in the classroom. As a kind of psychological environment of teaching, it will form a kind of pressure on students, thus restricting their behavior patterns; it can also affect students' emotions, thinking and participation in classroom teaching (Bosacki, 2005).

Reticent can form a tense environment easily and hinder students' free expression. If the classroom atmosphere is tense, both the communication between teachers and students and the communication within the student groups show the tendency of prudence and excessive attention; even a few active students will habitually think twice before the speech. Most individual classroom silence will eventually form group pressure and lead to 
collective reticent. In other words, if the majority of students actively participate in the classroom atmosphere, some timid, introverted students have a certain degree of motivation and encouragement, and therefore they will model the majority of students and open their mouth (Liu, 2005).

\section{(2) Class organization}

The original intention of class organization is to improve knowledge absorption. Desks and chairs are arranged in rows in a traditional way, which hinders a complex interaction. In other words, class organization forms affect the spatial organization forms of teaching physics, indirectly affect the relationship between teachers and students, and become an objective reason that can not be ignored to affect students' classroom reticent (Liu, 2005).

The arrangement of teachers' and students' seats affects the gap between teachers and students and finally affects teachers' teaching and learning methods. In China, the arrangement of seats is mainly in the form of "horizontal row" or "seedling field". Teachers are in the front, teachers' sovereignty and authority are emphasized; students are in the subordinate position, and they unconsciously form the habit of receptive learning. In addition, the result of such kind of permutation is that the opportunity and direction of communication between teachers and students depend on teachers' will, and the opportunity of communication between students is reduced to the minimum (Liu, 2005).

In actual teaching, teachers adopt a single "best" teaching mode of "teachers' speech" and "taking the overall situation into consideration", which makes it difficult for teachers and students to communicate with each other, and create a harmonious, relaxed and pleasant classroom atmosphere. In a large class teaching environment, students' abilities and habits are different, so it is difficult for teachers to take care of each student, which leads to the loss of learning enthusiasm and inevitably causes classroom reticent (Liu , 2005).

\section{Concluding Remarks}

The research results show that students' psychological factors, the relationship between teachers and students, the unique concept of "maintaining face" in Chinese traditional culture, and teachers' classroom teaching mode may all lead to classroom reticent. Teachers should treat students' reticent correctly, analyze the causes for negative silence, and adopt corresponding strategies to break classroom silence so as to improve their teaching effect and teaching quality. Teachers should realize the harm of teacher-centered teaching mode, prevent the occurrence of negative silence, and improve students' interest in learning and ultimately make classroom a platform for teachers and students to communicate in a free and relaxing way.

\section{ACKNOWLEDGEMENT}

This paper is one of the phased results of the "Research on the influencing mechanism of mobile phone addiction on College Students' classroom reticent in the era of mobile Internet" of the project of the Humanities and Social Sciences in Hubei Province (20Q035).

\section{References}

[1]. Petress. The Ethics of Student Classroom Silence [J]. Journal of Instructional Psychology, 2001:28(2),104-107.

[2]. Bilmes J. Constituting Silence: Life in the World of Total Meaning [J]. Semiotic, 1994 (09):73-87.

[3]. Qiao, C. On Students' Silence in English Classroom Teaching in Local Colleges and Universities from the 
Perspective of Students [J]. Education and occupation, 2010(11):189-191.

[4]. Schultz, K. Rethinking Classroom Participation: Listening to Silent Voices [M].New York, NY: Teachers College Press, 2009.

[5]. Teng, M. Teacher Factors of College Students' Silence in Class [J]. Heilongiiang Higher Education Research, 2009(04): 146-148.

[6]. Gu, X.(2005). The Influence of Chinese and American's Contrastive Views about Talk on Class Participation by Chinese and American Students[J]. CELEA Journal (Bimonthly), 28(5):40-44.

[7]. King, J. Silence in the Second Language Classroom of Japanese Universities [J]. Applied Linguistics, 2013:34(3): 325-343. DOI: https://doi.org/10.1093/applin/ams043

[8]. Eisenkraft Stacey F \& Yang H. Immigrant Chinese Student' s Use of Silence in the Language Arts Classroom: Perceptions, Reflections and Actions [J]. Teaching \& Learning, 2003:17 (2): 55-65.

[9]. Zhang, L. Research on College Students' Classroom Silence and Its Influencing Factors [D]. East China Normal University, 2015.

[10].Ollin R. Silent Pedagogy and Rethinking Classroom Practice: Structuring Teaching through Silence Rather Than Talk [J] Cambridge Journal of Education, 2008,38(2),265-280. DOI: https://doi.org/10.1080/03057640802063528

[11].Saylag R. An Exploration on the Silence in the Classroom within a Diagnostic Perspective: Whose Silence Is This? [J]. Procedia-Social and Behavioral Science, 2014,(114):527-532.

DOI: https://doi.org/10.1016/j.sbspro.2013.12.741

[12].Liu, X. On Classroom Silence [D]. Qufu Normal University, 2005.

[13].Bosacki S L. The Culture of Classroom Silence [M]. New York: Peter Lang, 2005. 